\title{
RELAÇÃO DIALÓGICA COM O CLIENTE SOBRE TRANSPLANTE RENAL: CUIDADO EDUCATIVO DE ENFERMAGEM*
}

\author{
Simone Aparecida Machado do Nascimento Ferreira ${ }^{1}$, Maria Luiza de Oliveira Teixeira ${ }^{2}$, \\ Elen Martins da Silva Castelo Branco ${ }^{3}$
}

\begin{abstract}
RESUMO: Objetivo: descrever os saberes de clientes renais crônicos sobre o transplante renal e discutir as contribuições desses saberes nos cuidados educativos de Enfermagem. Método: pesquisa convergenteassistencial, com 11 portadores de doença renal crônica aptos ao transplante, em hospital universitário da cidade do Rio de Janeiro. Realizaram-se entrevistas individuais entre março de 2016 a fevereiro de 2017. A análise foi de conteúdo temático. Resultados: os resultados trazem à reflexão que as pessoas em condições crônicas necessitam de ações integradas com a participação de várias áreas do saber em saúde. Torna-se indispensável que o cliente compartilhe a experiência de quem vive a cronicidade com os profissionais da saúde por meio do diálogo crítico-reflexivo. Conclusão: o diálogo possibilitou a reflexão sobre a construção e reconstrução de saberes e práticas sobre o transplante renal e revelou corresponsabilidade entre profissionais, clientes e seus familiares no processo recuperação do procedimento cirúrgico e manutenção do enxerto.
\end{abstract}

DESCRITORES: Enfermagem; Educação em saúde; Insuficiência renal crônica; Cuidados de enfermagem.

\section{DIALOGIC RELATIONSHIP WITH PATIENTS REGARDING KIDNEY TRANSPLANTATION: NURSING EDUCATIONAL CARE}

\begin{abstract}
Objective: to describe the knowledge of chronic kidney patients about kidney transplantation, and discuss the contributions of this knowledge to nursing educational care. Method: this is a convergent-care study with 11 chronic kidney disease patients who were eligible for transplantation, at a university hospital in the city of Rio de Janeiro. Individual interviews were conducted between March 2016 and February 2017, and their content submitted to thematic content analysis. Results: the results bring the reflection that chronically ill people need integrated actions with the participation of several areas of health knowledge. It is imperative that patients share the experience of those who live with chronic illnesses with health professionals through a critical-reflexive dialogue. Conclusion: the dialogue allowed the reflection on the construction and reconstruction of knowledge and practices about kidney transplantation, and revealed co-responsibility among professionals, patients and their families in the process of recovery from the surgical procedure, and graft maintenance.
\end{abstract}

DESCRIPTORS: Nursing; Health education; Chronic renal insufficiency; Nursing care.

\section{RELACIÓN DIALÓGICA CON EL PACIENTE SOBRE TRASPLANTE RENAL: CUIDADO EDUCATIVO DE ENFERMERÍA}

RESUMEN: Objetivo: describir os saberes de pacientes renales crónicos sobre trasplante renal y discutir las contribuciones de tales saberes en cuidados educativos de Enfermería. Método: Investigación convergente-asistencial, sobre 11 pacientes con insuficiencia renal crónica aptos para trasplante, en hospital universitario de Rio de Janeiro. Se realizaron entrevistas entre marzo de 2016 y febrero de 2017. Fue aplicado análisis de contenido temático. Resultados: Expresan la reflexión de que las personas con condiciones crónicas necesitan acciones integradas, con participación de varias áreas del saber en salud. Resulta indispensable que el paciente comparta la experiencia de quien vive la cronicidad con los profesionales de salud mediante el diálogo crítico-reflexivo. Conclusión: El diálogo permitió reflexionar sobre la construcción y reconstrucción de saberes y prácticas sobre trasplante renal, y reveló corresponsabilidad entre profesionales, pacientes y sus familiares en el proceso de recuperación del procedimiento quirúrgico y de preservación del injerto.

DESCRIPTORES: Enfermería; Educación en Salud; Insuficiencia Renal Crónica; Atención de Enfermería.

*Artigo extraído da dissertação de mestrado intitulada: Saberes e Práticas Compartilhados com Clientes Renais a Transplantar: Educação em Saúde para o Cuidado de Si. Escola de Enfermagem Anna Nery-UFRJ, 2017.

${ }^{1}$ Enfermeira. Mestre em Enfermagem. Enfermeira do Hospital Universitário Clementino Fraga Filho da Universidade Federal do Rio de Janeiro. Rio de Janeiro, RJ, Brasil.

${ }^{2}$ Enfermeira. Doutora em Enfermagem. Docente do Departamento de Enfermagem Fundamental da Escola de Enfermagem Anna Nery da Universidade Federal do Rio de Janeiro. Rio de Janeiro, RJ, Brasil.

${ }^{3}$ Enfermeira. Doutora em Enfermagem. Docente do Departamento de Enfermagem Fundamental da Escola de Enfermagem Anna Nery da Universidade Federal do Rio de Janeiro. Rio de Janeiro, RJ, Brasil.

Autor Correspondente:

Recebido: 07/05/2017

Maria Luiza de Oliveira Teixeira

Instituição vinculada: Escola de Enfermagem Anna Nery da Universidade Federal do Rio de Janeiro

Finalizado: 29/12/2017

Estrada do Tingui, 888 - 23075-007, Rio de Janeiro, RJ, Brasil

E-mail:mlot@uol.com.br 


\section{INTRODUÇÃO}

Doença Renal Crônica (DRC) é a lesão estrutural ou funcional nos rins, persistente por mais de três meses, e é classificada de acordo com a estimativa da taxa de filtração glomerular (TFG). Trata-se de doença de curso prolongado, de início insidioso e evolução assintomática ${ }^{(1)}$.

Variados fatores se associam à etiologia e à progressão para o declínio da função renal. Por exemplo, prevenir e tratar a diabetes, a hipertensão, a dislipidemia, a obesidade, a doença cardiovascular e o tabagismo, cujos controle e tratamento devem estar de acordo com as normatizações e orientações do Ministério da Saúde(2).

Há relação estreita entre o estágio da DCR com os desfechos do prognóstico. Para fins de atendimento integral, o tratamento consiste em medidas clínicas para retardar a piora da função renal, reduzir os sintomas e prevenir complicações quando nos estágios de um a três, pré-diálise, quatro e cinco, não dialítico, e Terapia Renal Substitutiva no estágio cinco, dialítico. Inicia-se no diagnóstico da DRC, mantém-se em longo prazo e, quanto mais precoce começar o tratamento conservador, maiores são as chances para preservar a função dos rins por mais tempo ${ }^{(3)}$.

Apesar do tratamento conservador, a DRC pode progredir para estágios avançados e, então, o cliente é preparado para a diálise ou o transplante. Cabe ressaltar que esses clientes têm o direito de optar pela realização ou não do transplante e, assim, afastar-se da dependência da máquina de hemodiálise ou da diálise peritoneal( ${ }^{(4)}$.

O transplante renal é uma cirurgia que consiste na ablação do órgão de um doador falecido ou vivo (parente ou não) e a sua implantação no receptor. Ele é indicado para pessoas com DRC em seu estágio cinco. No entanto, pode-se considerar o transplante preemptivo, ou seja, o transplante realizado antes de o paciente iniciar a terapia renal substitutiva ${ }^{(5)}$.

Como modalidade de escolha, o transplante renal contribui para maior sobrevida e melhor qualidade de vida, pois favorece ao sujeito retomar seu modo de vida, geralmente modificado pelos aspectos envolvidos com o tratamento dialítico ${ }^{(5)}$.

Embora o transplante renal seja uma forma de tratamento disponível e cada vez mais utilizada nos países da América Latina, a expansão não foi tão rápida como deveria ser para compensar o aumento da prevalência de pacientes na lista de espera. Dados do Registro Latino-Americano de Diálise e Transplante Renal mostram que, em 2010, foram realizados 10.397 transplantes renais, sendo $58 \%$ com doadores falecidos e os maiores percentuais aparecem no Uruguai $(96,8 \%)$, Cuba $(94,9 \%)$, Colômbia (92\%) e Argentina $(78,7 \%)^{(6)}$. No Brasil, a partir do ano de 2007, houve aumento considerável de transplantes com doador falecido. Desde então, se observa redução continuada no número de transplantes renais com doador vivo(7).

Em 2012, apesar de o Brasil ter sido o segundo colocado em números absolutos de transplante renal entre 30 países, com um total de 5.385 transplantes, ficando atrás apenas dos Estados Unidos, com 15.549 transplantes, este número ficou aquém da necessidade de 11.445 transplantes. Entre 2011 e 2013, houve 24.134 notificações de potenciais doadores no Brasil e, destes, apenas 28,9\% se tornaram doadores efetivos $^{(7)}$.

Os dados apontados são significativos, pois traduzem a realidade quanto ao crescimento de doentes com insuficiência renal crônica, que é considerada problema de ordem social e mundial, pois compromete o cotidiano do cliente, bem como de seus familiares, necessitando, assim, do envolvimento de todos os profissionais de saúde em medidas de educação e prevenção da DRC.

Tradicionalmente, a educação em saúde tem sido instrumento de disseminação, de afirmação de saber dominante, de responsabilização dos indivíduos pela redução dos riscos à saúde e culpabilização de danos. As críticas à política dominante, caracterizada pelas concepções reducionistas de saúde e doença do modelo biomédico, têm gerido muitos profissionais a trabalhar com alternativas de educação à saúde, como aquelas referenciadas na educação popular, como a de Paulo Freire, cuja concepção teórica valoriza o saber do outro entendendo que o conhecimento é um processo de construção coletiva( ${ }^{(8)}$. 
O cuidado educativo de Enfermagem ao cliente com DRC, pautado no diálogo, na reflexão e na crítica, permite a tomada de consciência ${ }^{(9)}$ de tudo que envolve o processo de transplante renal. Assim, o constructo "educação em saúde" aplica-se aqui como construtivo do cuidado e não como instrutivo. Para tanto, é importante acessar os saberes dos clientes renais crônicos, sobre transplante renal, para que se possa desenvolver um trabalho de educação em saúde aderente às necessidades do cliente e congruente com a sua realidade sociocultural.

Pelo exposto, o estudo apresenta como objetivos descrever os saberes de clientes renais crônicos sobre o transplante renal e discutir as contribuições desses saberes nos cuidados educativos de Enfermagem.

\section{METODOLOGIA}

Pesquisa qualitativa, de abordagem convergente-assistencial, pois favoreceu o envolvimento e a inclusão dos participantes no processo da pesquisa articulado à assistência. A principal característica da Pesquisa Convergente Assistencial (PCA) consiste na articulação da pesquisa com a prática assistencial. Pode ser aplicada como estratégia para a prática de educação em saúde, principalmente durante a coleta de informações ${ }^{(10)}$.

Na medida em que os dados foram obtidos, os cuidados de Enfermagem foram compartilhados por meio da educação em saúde durante o diálogo estabelecido na entrevista. A partir de uma relação dialógica, os temas foram problematizados com o cliente e isso possibilitou a reflexão crítica da realidade.

O estudo foi realizado no ambulatório de nefrologia de um hospital universitário, da cidade do Rio de Janeiro, no período de março de 2016 a fevereiro de 2017.

Foram eleitos os clientes com DRC em estágios quatro e cinco, maiores de 18 anos, de ambos os sexos, em tratamento conservador ou não, aptos ao transplante como terapia renal de substituição, por meio de doadores vivos e/ou falecidos, com nível de consciência e orientação capaz de responder às questões da pesquisa e assinar o Termo de Consentimento Livre e Esclarecido (TCLE). Os critérios de exclusão foram: clientes que não fizeram a opção pelo transplante renal; com problemas psiquiátricos e clientes especiais (deficientes mentais).

Para a obtenção dos dados, utilizaram-se a entrevista individual semiestruturada, o formulário de identificação sociocultural e os roteiros de discussão. Para a garantia do anonimato, foi utilizada a letra $P$, para a identificação das falas, seguida da sequência cronológica das entrevistas.

$\mathrm{Na}$ análise do material discursivo, aplicou-se a Análise de Conteúdo Temática, sendo a fase de categorização por Análise Temática. Nesta técnica, as categorias não são determinadas a priori, pois emergem das falas dos sujeitos ${ }^{(11)}$.

Os aspectos éticos foram atendidos repercutindo na aprovação do Comitê de Ética em Pesquisa da instituição proponente e coparticipante sob o parecer CEP 1.329.470.

\section{RESUlTADOS}

Considerou-se elegível o total de 17 clientes para participar da pesquisa. Entretanto, seis clientes se recusaram a participar da mesma. Desse modo, a pesquisa contou com a participação de 11 clientes, sendo sete $(63,6 \%)$ do sexo feminino. Com relação à faixa etária, uma $(9,0 \%)$ tinha idade inferior a 40 anos; três $(27,3 \%)$, na faixa de 40 a 50 anos; quatro $(36,4 \%)$ estavam inseridos na faixa etária de 50 a 60 anos e três $(27,3 \%)$, com idade entre 60 a 65 anos.

O diálogo entre a pesquisadora e os participantes iniciou-se com questões relacionadas à descoberta da doença e à escolha da terapia de substituição. Observou-se que cinco participantes não tiveram a oportunidade ou a opção de escolher sua terapia de substituição, sendo a hemodiálise um tratamento imediato, ou seja, de urgência. Tal fato se deu porque a descoberta ocorreu em curso avançado da doença, conforme as falas a seguir: 
Foi em 1991. [...] eu tive eclampsia, lá, descobriram que eu estava com lúpus, já estava paralisando os meus rins. Falou que meus rins tinham paralisado. (P1)

Há três anos atrás, [...] fiz os exames e, quando eu fiz os exames de sangue, o médico veio e me deu a notícia que meus rins tavam parando de funcionar. (P2)

Bem aí, agora, vai fazer dois anos, agora em novembro. [...] aí eu fiquei cinco dias internada, eu estava sentindo muita falta de ar. Aí, no mesmo dia que eu cheguei lá no hospital, eles me enfiaram logo um cateter. É um cateter! Pra poder fazer hemodiálise! (P10)

\section{Escolha pelo transplante renal}

A escolha ocorreu de forma ingênua, pois os clientes desconheciam ou não consideravam as implicações futuras dessa nova situação de vida. Destacaram o fato de não querer ir para a hemodiálise e informaram pavor das agulhas, da máquina, do sofrimento causado por esta terapia:

[...] é que eu vi que havia uma possibilidade de ter uma vida nova através de um transplante. (P2)

Porque eu decidi, porque a doutora sempre falou pra mim que sua taxa está $17 \%$ (taxa de filtração glomerular). E que pra eu fazer o mais rápido porque, senão, eu teria que ir para máquina, daí em fiquei com medo! (P6)

Bem, se deu pela melhor condição de vida que eu vou ter. Então, eu estava fazendo uso de vários medicamentos e vi que a situação não estava melhorando. Então, eu optei de fazer o transplante devido uma melhora, sei lá, melhorar a condição de saúde, não é? (P9)

\section{Expectativas e perspectivas de mudanças após o transplante}

As falas demonstram as expectativas e perspectivas de mudanças a partir de experiências a serem vividas após o transplante.

Eu acho que vai melhorar bastante, né? Uma coisa eu tenho certeza que vai mudar: que eu não vou precisar fazer mais hemodiálise! Eu vou voltar, assim, a sair mais!... Entendeu? Viajar, o que eu mais gosto de fazer! O que eu não fazia agora eu vou poder fazer. (P1)

É, eu espero que fique normal, né? Quer dizer, eu já vivo uma vida normal! Eu espero que fique melhor ainda, né? (P2)

[...] a qualidade de vida deve melhorar, não é? Porque deve reduzir a quantidade de medicamento que hoje eu tomo, que eu faço uso. É, o uso deve diminuir e, mediante a isso, eu ganhar uma qualidade de vida melhor. (P9)

Como um atleta, um super-herói! (Risos...). O homem de ferro! (Risos). (P4)

Observou-se que existe carência de informações quanto ao transplante, pois P3 acredita que, após o transplante, não necessitará vir ao hospital com tanta frequência e P4 se compara a um super-herói.

\section{Retorno do centro cirúrgico após o transplante renal}

Dos 11 participantes do estudo, uma cliente foi submetida ao transplante anteriormente e fará outro novamente. Durante o diálogo, ao falar sobre sua experiência com o transplante, ela informou que, ao retornar do centro cirúrgico, estava com cateter em acesso profundo:

Sei, já coloquei! Aquele do pescoço? O médico me disse quando fui colocar o cateter peritoneal! (P3)

Outro participante, apesar de não ter a experiência de um transplante anterior, conseguiu associá-la à cirurgia cardíaca feita pelo pai, que retornou do centro cirúrgico com um dreno. O diálogo abaixo destaca esta associação: 
Eu me lembro do dreno, quando o meu pai fez cirurgia cardíaca, colocaram um dreninho aqui embaixo! (Nesse momento, mostra com o dedo indicador o local de inserção do dreno) (P7)

Os demais participantes demonstraram desconhecimento quanto ao retorno do centro cirúrgico no que diz respeito a equipamentos acoplados, como cateteres e sondas. Evidenciaram preocupação quanto ao tempo de internação e de permanência dos equipamentos, conforme é destacado a seguir:

E até quando ficamos assim? (P2)

Isso em quantos dias? (P2)

Outra preocupação emergente, nem sempre considerada quando se pensa em terapia de substituição, é a estética corporal, conforme evidenciado nas falas de P3. Tal preocupação foi destacada quando a pesquisadora utilizou do recurso da ilustração para explicar como se dá a incisão na cirurgia de transplante renal.

Ah, a incisão não é por trás! É pela frente! [...] ainda bem! Porque não vou ficar

sem umbigo! [Risos] (P3)

Nesse momento, foi oportuno explicar que a cicatriz umbilical permanecerá e, assim, um visível alívio, por meio da expressão facial, foi demonstrado por P3.

\section{Saberes sobre o enxerto e complicações pós-transplante}

Durante o diálogo, evidenciou-se que alguns participantes idealizam que o enxerto tem a duração equivalente ao próprio tempo de vida e que o transplante é a cura da DRC. As falas dos participantes, em relação à localização do rim a ser transplantado e à vida útil de enxerto, foram expressivas:

Não me falaram nada sobre isso não! O quê? O tempo de vida? Pra vida toda, não, não é? Mas ...(P7)

Nossa! Essa eu não sabia! [Mostra-se triste, preocupado, pensativo] (P9)

Os clientes são considerados doentes renais, mas transplantados renais são susceptíveis a intercorrências clínicas. A realização do transplante renal não é a garantia de sucesso do funcionamento do enxerto visto que há a possibilidade de disfunção do enxerto por episódios de rejeição, infecções bacterianas, virais e problemas decorrentes do uso de drogas nefrotóxicas e outras.

O participante que fará o transplante pela segunda vez, quando abordado o tema sobre complicações pós-transplante, relaciona a rejeição como uma das complicações:

Bem, hoje eu saberia, pela dor forte que dá! E também quando a minha urina fosse diminuindo! Se eu estou acostumada a ir umas cinco vezes por dia e eu começar a ir três, duas e aí sai pouco líquido, aí eu já estou sabendo que está acontecendo alguma coisa! (P1)

Febre também! (P1)

Outras complicações citadas foram a inflamação, a dor, o inchaço, a infecção, a febre, o mal-estar e a perda do enxerto. Muitas destas complicações foram apresentadas na forma de questionamento durante o diálogo e tais questionamentos foram discutidos entre a pesquisadora e os participantes:

Inflamação, dor, inchaço. (P2)

Sim, no caso, essa infecção, ela vem precedida de quê? Qual são os sintomas da infecção? Por exemplo: Infecção urinária? Quais são os sintomas que eu posso sentir? Dor? Febre? [...] então, essa infecção pode virar uma rejeição? Ou já é uma rejeição? (P9)

\section{- DISCUSSÃO}

A linha que separa a saúde e a doença, por vezes, é tênue e, em enfermidades silenciosas, os sintomas ocorrem tardiamente. A DRC tem se constituído como um crescente problema de saúde pública e, anualmente, aumenta o número de clientes em estágio final cujo tratamento seja o transplante renal. 
Entretanto, a desigualdade entre a procura e a oferta de rins é a causa da demora do transplante. No Brasil, em média, 30\% das pessoas que aguardam na fila recebem o órgão por ano ${ }^{(12)}$.

A DRC possui estágios de evolução gradativa, com diagnóstico geralmente em fase avançada, por conta de um quadro clínico praticamente oculto. Associa-se à elevada mortalidade, morbidade e custos, pois os transplantes fazem parte dos recursos do Sistema Único de Saúde (SUS). Além disso, impacta negativamente a qualidade de vida, pois o caráter silencioso, a lenta progressão, as fragilidades na prevenção e as comorbidades da atualidade desvelam uma situação preocupante na saúde pública mundial ${ }^{(12)}$.

Os clientes participantes deste estudo confirmaram tais afirmativas. A partir da descoberta da DRC, já iniciaram a hemodiálise, uma terapia que os aprisiona à máquina e ao uso de grande número de medicamentos que traz desconforto físico, pelas punções sucessivas, e diminui a qualidade de vida. Eles percebem o tratamento dialítico, ou seja, a hemodiálise como prisão, dor e sofrimento.

As várias expectativas, perspectivas de mudanças e as experiências vividas durante a hemodiálise conduziram os clientes a idealizar que o transplante renal é uma opção que apresenta vantagens imediatas à hemodiálise. O transplante renal pode proporcionar melhor qualidade de vida. Com exceção da medicação diária e das consultas de rotina, o transplantado tem oportunidade de direcionar seus interesses e atividades ${ }^{(13)}$.

Os saberes dos participantes do estudo, relacionados à escolha do transplante renal, se mostram como possibilidade de mudança, mas não foram considerados os cuidados necessários para a manutenção deste transplante como, também, tinham conhecimentos fragmentados sobre as possíveis complicações. Tais lacunas no conhecimento são preocupantes, pois podem levar ao comprometimento do órgão transplantado.

Ao considerar a liberdade, a autonomia e a esperança, algumas práticas precisam ser repensadas e reconstruídas, pois o indivíduo não se afastará do hospital, não terá a força do herói idealizado e tão pouco deixará de tomar medicamentos. Dessa forma, o diálogo desmistifica crenças e valores conduzindo à reflexão e, assim, favorece o cuidado após o transplante.

As dúvidas e incertezas pelas quais passam os clientes que irão se submeter a um transplante renal fazem com que elas reafirmem a ausência de cuidados e/ou tratamento no período pós-transplante dificultando seu enfrentamento quando estas situações emergirem no período pós-transplante ${ }^{(14)}$.

O processo de transplantar implica realidades a serem construídas e reconstruídas por meio do diálogo, do despertar do senso crítico e do compartilhar de saberes acerca do mesmo e suas implicações. Mesmo diante do transplante bem-sucedido, após a alta e com o enxerto funcionante, o cliente convive com uma doença crônica. Após receber o enxerto renal, está sempre correndo risco de rejeição.

Apesar dos avanços em transplante reduzirem a incidência de rejeição aguda para menos de $15 \%$ e aumentarem a sobrevida do enxerto de um ano para mais de $90 \%$, a taxa de sobrevida do enxerto em longo prazo permanece inalterada ou aproximadamente em 50\% dez anos após o transplante ${ }^{(15-16)}$.

É necessário que o mesmo receba orientações adequadas para poder conviver com a possibilidade concreta de rejeição e com o novo modo de vida que terá de assumir. A saber, sem as sessões de hemodiálise, há dependência do uso diário e correto das medicações imunossupressoras, fator que influencia no tempo de funcionamento do rim transplantado ${ }^{(17) .}$

O rim transplantado também pode ser acometido por algumas doenças que poderão alterar sua função como as infecções urinárias, obstruções na via de saída de urina e rejeições aguda ou crônica. Devido à presença de complicações, rejeição ou não suficiência do enxerto, o transplante renal pode significar uma interrupção abrupta das expectativas do sujeito transplantado representando a necessidade de retornar ao tratamento dialítico e convivendo com as nuances deste ou até mesmo com a morte ${ }^{(14)}$.

No cotidiano da prática assistencial, o enfermeiro é desafiado a prover assistência com qualidade aos clientes e familiares e confrontado com a necessidade de definir o seu papel no processo do cuidar acerca do transplante e sua importância. Cabe enfatizar que pessoas em condições crônicas necessitam 
de ações integradas com a participação de várias áreas do saber em saúde. A abordagem da equipe multiprofissional potencializa o cuidado das DRC e suas comorbidades ${ }^{(18)}$. Para isso acontecer, se faz indispensável uma efetiva comunicação entre os profissionais e o cliente, que possui a experiência de quem vive a cronicidade, gerando a interdisciplinaridade no cuidado segundo conceitos éticos.

Desse modo, se estabelece um processo de confiança com o cliente, tanto os profissionais de Enfermagem, quanto para qualquer profissional da área da saúde, por meio da afetividade, tolerância, flexibilidade, fidelidade, aprimoramento constante, respeito, confiabilidade, boas maneiras e competência técnica.

A orientação em saúde tem convergência com a pedagogia da autonomia em que os clientes compartilham saberes e práticas de forma democrática. Os profissionais devem assumir o cuidado com os clientes proporcionando a liberdade necessária para que eles acessem esses saberes e práticas.

O estudo apresentou, como limitações, as mudanças ocorridas na agenda das consultas médicas prétransplante e a inexistência de ambulatório para a consulta de Enfermagem, conforme preconizado pelo Ministério da Saúde, devido às dificuldades de recursos humanos.

\section{CONSIDERAÇÕES FINAIS}

São várias as prioridades para o sucesso do transplante renal, bem como são as fragilidades impostas pela situação da cronicidade da doença, tratamento e cirurgia. O conhecimento fragmentado e ingênuo apresentado pelos participantes revela corresponsabilidade entre profissionais, clientes e seus familiares no processo recuperação do procedimento cirúrgico e manutenção do enxerto.

Como integrante da equipe de saúde, o enfermeiro desempenha papel relevante no que se refere à modalidade de tratamento e as orientações advindas dessa escolha. Nesse contexto, o papel do enfermeiro transcende o ato de orientar para favorecer a conscientização das pessoas, ou seja, a percepção que elas têm de si, a respeito da situação em que vivem e das consequências de suas escolhas para a saúde, tornando-as sujeitos autônomos na relação do cuidar.

O cuidar em Enfermagem considera a educação em saúde, a relação de diálogo e a reflexão. Nesse processo, deve-se aprofundar a utilização da pesquisa convergente- assistencial para a prática da Enfermagem.

\section{REFERÊNCIAS}

1. Bastos MG, Kirsztajn GM. Doença renal crônica: importância do diagnóstico precoce, encaminhamento imediato e abordagem interdisciplinar estruturada para melhora do desfecho em pacientes ainda não submetidos à diálise. J. Bras. Nefrol. [Internet] 2011;33(1) [acesso em 09 jun 2017]. Disponível: http://dx.doi.org/10.1590/S0101-28002011000100013.

2. Ministério da Saúde (BR). Secretaria de Atenção à Saúde. Departamento de Atenção Especializada e Temática. Diretrizes Clínicas para o Cuidado ao paciente com Doença Renal Crônica - DRC no Sistema Único de Saúde. [Internet] Brasília: Ministério da Saúde; 2014 [acesso em 27 nov 2017]. Disponível: http://bvsms.saude.gov.br/bvs/publicacoes/diretrizes_ clinicas_cuidado_paciente_renal.pdf.

3. Machado GRG, Pinhati FR. Tratamento de diálise em pacientes com insuficiência renal crônica. Cadernos UniFOA [Internet] 2014;9(26) [acesso em 09 jun 2017]. Disponível: http://web.unifoa.edu.br/cadernos/edicao/26/137-148.pdf.

4. Chandna SM, Carpenter L, da Silva-Gane M, Warwicker P, Greenwood RN, Farrington K. Rate of Decline of Kidney Function, Modality Choice, and Survival in Elderly Patients with Advanced Kidney Disease. Nephron. [Internet] 2016;26(5) [acesso em 27 nov 2017]. Disponível: https://doi.org/10.1093/ndt/gfq630.

5. Santos CM, Kirchmaier FM, Silveira WJ, Arreguy-Sena C. Percepções de enfermeiros e clientes sobre cuidados de enfermagem no transplante de rim. Acta paul enferm. [Internet] 2015;28(4) [acesso em 09 jun 2017]. Disponível: http:// dx.doi.org/10.1590/1982-0194201500057. 
6. Pecoits-Filho R, Rosa-Diez G, Gonzalez-Bedat M, Marinovich S, Fernandez S, Lugon J et al. Tratamento substitutivo da função renal na doença renal crônica: uma atualização do Registro Latino-Americano de Diálise e Transplante. J. Bras. Nefrol. [Internet] 2015;37( 1) [acesso em 29 abr 2017 ]. Disponível: http://dx.doi.org/10.5935/0101-2800.20150002.

7. Associação Brasileira de Transplante de Órgãos (ABTO). Registro Brasileiro de Transplantes. Dimensionamento dos Transplantes no Brasil e em cada estado (2009-2016) São Paulo: ABTO; 2016. [acesso em 09 jun 2017]. Disponível: http:// www.abto.org.br/abtov03/Upload/file/RBT/2016/RBT2016-leitura.pdf.

8. Ministério da Saúde (BR). Secretaria de Atenção à Saúde. Núcleo Técnico da Política Nacional de Humanização. Acolhimento nas práticas de produção de saúde. Humaniza SUS. Caderno de Textos. Cartilhas da Política Nacional de Humanização. [Internet] Brasília: Ministério da Saúde; 2010. [acesso em 09 jun 2017]. Disponível: http://bvsms.saude.gov. br/bvs/publicacoes/caderno_textos_cartilhas_politica_humanizacao.pdf.

9. Freire P. Extensão ou comunicação. Rio de Janeiro (RJ): Paz e Terra; 2017.

10. Bonetti, A, Silva DMGV, Trentini, M. O método da pesquisa convergente assistencial em um estudo com pessoas com doença arterial coronariana. Esc. Anna Nery [Internet] 2013;17(1) [acesso em 09 jun 2017]. Disponível: http://dx.doi. org/10.1590/S1414-81452013000100025.

11. Bardin L. Análise de conteúdo. Trad. Luís Antero Reto e Augusto Pinheiro. São Paulo: Edições 70; 2011.

12. Batista CMM, Moreira RSL, Pessoa JLE, Ferraz AS, Roza BA. Perfil epidemiológico dos pacientes em lista de espera para o transplante renal. Acta paul. enferm. [Internet] 2017;30(3) [acesso em 12 dez 2017 ]. Disponível: http://dx.doi. org/10.1590/1982-0194201700042.

13. Cardoso JS, Cavalcante MCV, de Miranda ATM. A reabilitação profissional como proposta. Rev. Ter. Ocup. Univ. [Internet] 2013,24(2) [acesso em 09 jun 2017]. Disponível: http://dx.doi.org/10.11606/issn.2238-6149.v24i2p162-167.

14. dos Santos CM, Kirchmaier FM, Silveira WJ, Arreguy-Sena C. Percepções de enfermeiros e clientes sobre cuidados de enfermagem no transplante de rim. Acta paul. enferm. [Internet] 2015;28(4) [acesso em 07 Maio 2017]. Disponível: http:// dx.doi.org/10.1590/1982-0194201500057.

15. McDonald S. Russ G. Campbell S, Chadban S. Kidney Transplant Rejection in Australia and New Zealand: Relationships Between Rejection and Graft Outcome. American Journal of Transplantation. [Internet] 2007;7(5) [acesso em 12 dez 2017 ]. Disponível: http://dx.doi.org/doi:10.1111/j.1600-6143.2007.01759.x.

16. Fernandes IMM.; Filho, MA. Disfunção Crônica do enxerto renal. Causas, evolução e prevenção. Módulo3 - Curso "Cuidado do paciente com transplante renal". [Internet] 2016. [acesso em 17 out 2016]. Disponível: http://cursos.evimed. net/pt-br/trasplante_programa.

17. Lira ALBC, Lopes MVO. Pacientes transplantados renais: análise de associação dos diagnósticos de enfermagem. Rev. Gaúcha Enferm. [Internet]. 2010;31(1) [acesso em 12 dez 2017]. Disponível: http://dx.doi.org/10.1590/S198314472010000100015.

18. Bayliss EA, Bhardwaja B, Ross C, Beck A, Lanese DM. Multidisciplinary team care may slow the rate of decline in renal function.Clin J Am SocNephrol. [Internet] 2011;6(4) [acesso em 27 nov 2017]. Disponível: http://cjasn.asnjournals. org/content/6/4/704.full.pdf+html. 